\title{
A Indicação Geográfica do café da Serra da Mantiqueira de Minas Gerais como ferramenta de desenvolvimento territorial
}

\author{
The Coffee Geographic Indication in Serra da Mantiqueira in Minas Gerais as a \\ tool for territorial development
}

\section{La Indicación Geográfica del café de la Serra da Mantiqueira en Minas Gerais como herramienta de desarrollo territorial}

\author{
Maria Helena Facirolli Sobrinho ${ }^{1}$ \\ Cezar Augusto Miranda Guedes ${ }^{1}$ \\ Maria Cristina Drumond e Castro ${ }^{1}$
}

Recebido em 27/10/2018; revisado e aprovado em 13/08/2019; aceito em 19/09/2019

DOI: http://dx.doi.org/10.20435/inter.v22i1.2206

\begin{abstract}
Resumo: A pesquisa parte da perspectiva de que as Indicações Geográficas podem ancorar uma estratégia de desenvolvimento territorial por conter particularidades que diferenciam o território. Por meio do estudo de caso do café da Serra da Mantiqueira, a pesquisa verificou que a obtenção do registro de Indicação Geográfica e as contínuas melhorias no processo de produção do café contribuem para o desenvolvimento do território.

Palavras-chave: Indicações Geográficas; desenvolvimento local; café da Serra da Mantiqueira.

Abstract: This research starts from the perspective that the Geographic Indications can anchor a strategy of territorial development, as it contains peculiarities that differ the territory. Through a case study of the coffee in the Serra da Mantiqueira, the research demonstrated that obtaining the record of the Geographic Indication and its continuous improvement in the process of coffee production contribute to the development of the territory
\end{abstract}

Keywords: Geographic Indications; local development; Serra da Mantiqueira's Coffee.

Resumen: La investigación parte de la perspectiva de que las Indicaciones Geográficas pueden anclar una estrategia de desarrollo territorial, pues contienen particularidades que diferencian el territorio. Por medio del estudio de caso del café de la Serra da Mantiqueira, la investigación verificó que la obtención del registro de Indicación Geográfica y las continuas mejoras en el proceso de producción del café contribuyen al desarrollo del territorio

Palabras claves: indicaciones geográficas; desarrollo local; café de la Serra da Mantiqueira.

\section{INTRODUÇÃO}

O reconhecimento de produtos e serviços, devido às suas características especiais, vinculadas à sua qualidade e origem, constitui um assunto de grande relevância no contexto atual. Existem discussões na perspectiva de que o desenvolvimento territorial poderia ser dinamizado por intermédio das Indicações Geográficas (IGs). Alguns países, especialmente os europeus mais ao sul do continente, há tempos vêm utilizando a proteção jurídica proporcionada pelo registro das Indicações Geográficas como forma de tornar seus produtos mais competitivos e desenvolver regiões menos favorecidas.

Em Minas Gerais, região sudeste do Brasil, a Serra da Mantiqueira é uma cadeia montanhosa que reúne condições especiais que contribuem para o desenvolvimento territorial. Por ser uma região de elevada altitude, composta por uma topografia particular com padrão climático saudável, está apta para a produção de cafés especiais. Diante dos atributos tangíveis e intangíveis do território, os atores locais buscam estabelecer o café como um produto de qualidade e,

\footnotetext{
${ }^{1}$ Universidade Federal Rural do Rio de Janeiro (UFRRJ), Seropédica, Rio de Janeiro, Brasil.
} 
portanto, diferenciado. Vale registrar que as áreas de montanha são consideradas mais aptas à valorização do rural não agrícola, assim como à produção diferenciada de produtos ancorados ao território, já que as condições para a implementação de uma agricultura industrializada são reduzidas (LÓPES NETTO et al., 2015).

Diante dessa premissa, a presente pesquisa tem o objetivo de identificar como as Indicações Geográficas podem ser consideradas um fator de desenvolvimento territorial, utilizando como estudo de caso o café da Serra da Mantiqueira de Minas Gerais. Para tanto, buscou-se caracterizar o território que produz o café com Indicação de Procedência e identificar como os atores locais podem contribuir para o desenvolvimento da região.

Neste trabalho, além da introdução e conclusão, aborda-se num primeiro momento o referencial teórico, com noções de desenvolvimento territorial, Indicações Geográficas e cafés especiais. A seguir, é apresentada a metodologia empregada e, para finalizar, são expostos os resultados e discussões.

\section{REFERENCIAL TEÓRICO}

Nos últimos anos, principalmente na Europa, tem se acentuado a importância dos produtos agroalimentares com identidade cultural, tais como bebidas, lácteos, carnes etc., para promover o desenvolvimento de áreas rurais. O interesse pelo tema das Indicações Geográficas, nos países latino-americanos, foi despertado em função do êxito das políticas de desenvolvimento da União Europeia (EU). É neste contexto que surgem no Brasil as discussões acerca das Indicações Geográficas como indutoras do desenvolvimento territorial.

A expressão desenvolvimento territorial pode ser definida como "todo processo de mobilização dos atores que leve à elaboração de uma estratégia de adaptação aos limites externos, na base de uma identificação coletiva com uma cultura e um território" (PECQUEUR, 2005, p. 12). Para o autor, no processo de desenvolvimento, não cabe sua implantação por meio de decreto, mas constituindo uma construção dos atores. Assim, em um ambiente de globalização e com consequente crescimento da concorrência, compete aos atores locais reagirem a esse processo e adotarem estratégias que permitam a reorganização da economia local. Dentro dessa lógica, devem buscar os recursos próprios do território que permitam a diferenciação ${ }^{2}$ de seus produtos.

O território não se restringe simplesmente a uma realidade física ou geográfica, mas a "uma realidade complexa, ao mesmo tempo humana, social, cultural e histórica. Isso significa que as mesmas condições técnicas e financeiras não geram os mesmos efeitos econômicos em termos de desenvolvimento em dois territórios diferentes" (CARRIÈRE; CAZELLA, 2006, p. 36). Assim, fatores como solo, paisagem, clima, cultura, tradições, o saber-fazer, as edificações, os museus, os arquivos históricos e as relações sociais são concebidas como condições territoriais de desenvolvimento (SAQUET E BRISKIEVICZ, 2009; SAQUET, 2013).

Neste contexto, os territórios que dispõem de recursos específicos e não transferíveis de um local para outro têm o potencial de gerar desenvolvimento. Tais recursos podem ser tangíveis ou intangíveis. Sob esta ótica, Pecqueur (2005) apresenta a diferença entre recursos

\footnotetext{
${ }^{2}$ Um produto se encontra diferenciado quando se pode distinguir o bem ou serviço de um vendedor em relação a outro vendedor qualquer. Isto é, trata-se de um produto que não é homogêneo; desse modo, fornecedores de produtos diferenciados podem cobrar um preço acima do praticado no mercado. A esse respeito, pode-se consultar Chamberlin (1956).
} 
e ativos, ademais os qualifica como genéricos ou específicos. Assim, os recursos territoriais são "os fatores a explorar, organizar, ou ainda revelar" (PECQUEUR, 2005, p. 13), enquanto os ativos representam fatores de produção em ação. Um processo de especificação de ativos consiste em transformar recursos específicos em ativos específicos, o que possibilita a um território tornar-se diferenciado.

Champedronde (2012), ao considerar o território como substrato da atividade econômica, menciona o fenômeno da ancoragem (vinculação) de um determinado produto ao seu território de origem. A caracterização da ancoragem de qualquer produto sugere que se deve levar em conta os seguintes elementos: a) o enraizamento territorial do grupo humano (comunidade local) que realiza a produção, o processamento, seu mercado e seu consumo; b) a inclusão do produto no contexto do repertório de elementos da cultura desse grupo humano; e c) a aptidão do produto em se enquadrar como uma referência de identidade desse mesmo grupo humano.

\subsection{Indicações Geográficas e desenvolvimento}

Desde épocas passadas, quando se fazia referência a produtos, relacionava-os ao seu local de origem. Na Grécia Antiga, era comum estabelecer uma analogia do produto ao território pertencente, como os vinhos de Corinto, o mel da Sicília e o mármore de Paros. Na Europa, existem mais de 1.900 vinhos e mais de 1.000 produtos de origem agrícola e gêneros alimentícios com algum tipo de proteção. Alguns exemplos podem ser citados, como o queijo Roquefort e o Champagne, na França; o presunto Parma e o queijo Parmigiano Reggiano, na Itália; e o azeite de oliva Montes de Toledo, na Espanha. Na América Latina, o café de Vera Cruz e a tequila, no México, e os charutos cubanos e o café da Colômbia se fazem presentes (VALENTE et al., 2012).

Neste viés, as Indicações Geográficas relacionam-se a uma qualidade conferida a um produto que se origina de um território cujas especificações estão atreladas à sua origem geográfica. Sob este ponto de vista, Pereira, Lourenzani e Watanabe (2018) ressaltam que, diante da crescente valorização de produtos vinculados à sua origem e qualidade, houve maior necessidade de regulamentação das Indicações Geográficas. De acordo com essa abordagem, Belas (2013) afirma que, desde os fins do século XIX, mais especificamente no ano de 1883, a Convenção da União de Paris (CUP) estabeleceu a primeira legislação internacional acerca da proteção da propriedade industrial.

Ao longo dos anos, no intuito de perfeiçoar e tornar mais consistentes as normas estabelecidas pela CUP, diversos acordos e mudanças foram instituídos. Entre eles, pode-se mencionar o Acordo de Madrid, firmado em 1891, e o Acordo de Haia, em 1925. Ambos visavam repreender as falsas indicações de proveniência. Em 1958, foi instituído o Acordo de Lisboa, no qual os nomes geográficos passaram a ter proteção em nível internacional, com destaque especial para a Denominação de Origem.

Em 1994, na última rodada do Acordo Geral sobre Tarifas e Comércio (GATT) no Uruguai, foi consolidado o Acordo sobre Aspectos de Direitos de Propriedade Intelectual Relacionados com o Comércio (ADPIC ou TRIPS em inglês). Diante desse contexto, em 1995, o assunto referente à Propriedade Industrial voltou a ser discutido com a criação da Organização Mundial do Comércio (OMC). Bruch (2013) refere-se a tal concepção enfatizando que um dos pontos importantes instituído na OMC diz respeito à negociação e aprovação do ADPIC/TRIPS. Ficou estabelecido que este acordo seria obrigatório para todos os membros da OMC. Ademais, o ADPIC não adota 
um registro para as Indicações Geográficas no âmbito internacional. Para reconhecimento e validação de uma IG, faz-se necessário recorrer ao órgão competente, que, no caso do Brasil, é representado pelo Instituto Nacional de Propriedade Industrial (INPI).

No Brasil, a Lei n. 9.279, de 14 de maio de 1996, é que regulamenta os direitos e as obrigações relativos à Propriedade Industrial. A Indicação Geográfica está disciplinada no Título IV, nos Art. 176 a 182. A lei não define o que é uma IG, entretanto institucionaliza legalmente duas espécies: a Indicação de Procedência (IP) e a Denominação de Origem (DO), cuja definição encontra-se nos artigos 177 e 178, apresentados a seguir:

Art. 177: Considera-se indicação de procedência o nome geográfico de país, cidade, região ou localidade de seu território, que se tenha tornado conhecido como centro de extração, produção ou fabricação de determinado produto ou de prestação de determinado serviço.

Art. 178: Considera-se denominação de origem o nome geográfico de país, cidade, região ou localidade de seu território, que designe produto ou serviço cujas qualidades ou características se devam exclusiva ou essencialmente ao meio geográfico, incluídos fatores naturais e humanos. (BRASIL, 1996, p. 11).

Segundo dados publicados pelo INPI (s.d.), a primeira Indicação Geográfica brasileira a ser reconhecida foi a do Vale dos Vinhedos, em 2002. Atualmente, existem 64 Indicações Geográficas brasileiras registradas. Dessas, 53 foram registradas como Indicação de Procedência e 11 como Denominação de Origem. Vale ressaltar que também constam oito Denominações de Origem estrangeiras reconhecidas no INPI, sendo elas: Região dos Vinhos Verdes (Portugal); Cognac (França); vinhos Franciacorta (Itália); coxas de suínos frescas; presunto defumado e cru San Daniele (Itália); Porto (Portugal); vinhos Napa Valley (Estados Unidos); Champagne (França) e o queijo Roquefort (França).

Na concepção de Valente et al. (2012), um dos objetivos de uma Indicação Geográfica é a proteção conferida aos produtos da região. Essa proteção beneficia consumidores na medida em que fornece garantias quanto à qualidade e procedência do produto. Favorece, também, os produtores que têm interesses comerciais e ficam submetidos a regras específicas de produção. Para Guedes e Silva (2014), um ponto importante "é a defesa dos produtores em relação a comportamentos concorrenciais lesivos e oportunistas na utilização indevida do nome do produto" (GUEDES; SILVA, 2014, p. 413).

As IGs tornam os produtos diferenciados e únicos, podendo, dessa forma, agregar valor a eles. Nesse contexto, Chambelim (1956), em 1933, na obra intitulada Teoría de la competencia monopólica, argumenta que a diferenciação pode se dar por meio de qualidade, desenho, reputação, entre outros fatores.

Velloso (2008) chama atenção para o fato de que "embora as Indicações Geográficas não tenham sido concebidas para promover o desenvolvimento territorial, elas podem servir como ferramenta para tal" (VELLOSO, 2008, p. 44). Para tanto, são necessárias estratégias e projetos, bem como a participação dos atores locais.

Neste viés, existem na literatura discussões que apontam o potencial das IGs enquanto ferramenta de desenvolvimento territorial rural. Entre os argumentos, pode-se citar: valorização dos produtos locais; agregação de valor; elevação da renda; estímulo à cooperação; ampliação do mercado; valorização do saber-fazer; proteção contra concorrência desleal aos produtores; valorização das propriedades rurais; conservação da biodiversidade; elevação de serviços vinculados ao turismo; e multifuncionalidade do meio rural (NIEDERLE, 2009). 
Em uma pesquisa desenvolvida por Vandecandelaere et al. (2018), foi possível verificar os vários tipos de impactos (impacto no preço e na renda; na produção; no acesso ao mercado e na competitividade; e no nível territorial) proporcionados por uma IG. Para tanto, os autores analisaram nove casos de produtos com Indicação Geográfica, sendo eles: o café da Colômbia (Colômbia); o chá Darjeeling (Índia); o repolho Futog (Sérvia); café Kona (Havaí); queijo Manchego (Espanha); pimenta Penja (Camarões); açafrão Taliouine (Marrocos); queijo Tête de Moine (Suíça); e o Vale dos Vinhedos (Brasil).

Vandecandelaere et al. (2018) identificaram os seguintes resultados: a) impactos nos preços: a implementação de uma Indicação Geográfica elevou de modo considerável o preço do produto final ou da matéria-prima em todos os nove casos estudados. Esse resultado vale independentemente do tipo de produto em consideração (café, chá, vinho etc.), a região de origem (Europa, África, América) e se a Indicação Geográfica foi estabelecida há muito tempo ou registrada recentemente; b) impactos no volume de produção: em todos os casos estudados, com exceção do chá Darjeeling, o processo de Indicação Geográfica afetou o volume de produção, conquanto apresentando diferença no curto e longo prazos; c) diversificação de mercado: a IG eleva o número de países de destino de suas exportações; e d) impactos no nível territorial: embora não tenha sido objeto de análise, uma relação entre os processos de Indicação Geográfica e o turismo foi observada em quase todos os casos.

Desse modo, as IGs têm o potencial de promover o desenvolvimento territorial por intermédio de ações específicas que recaiam sobre o desenvolvimento local (como o turismo, por exemplo), sobre o patrimônio e por fatores vinculados a demandas sociais, tais como o comércio justo e paisagens (CERDAN, 2013).

\subsection{A importância do café na economia brasileira}

O Brasil, durante décadas, vem se destacando como maior produtor de café do mundo. No que tange à exportação mundial, o Brasil lidera este segmento, seguido por Vietnã e Colômbia. Cabe ressaltar que, entre os principais estados produtores de café no Brasil, o destaque maior é Minas Gerais, pois a participação relativa deste estado na produção de café representa cerca de $50 \%$ do total produzido no país (CONSELHO DOS EXPORTADORES DE CAFÉ DO BRASIL [CECAFÉ], 2018). Dessa forma, pode-se apreender que o café é um produto de extrema importância para a economia brasileira.

No início dos anos de 1990, o setor cafeeiro brasileiro passou por mudanças decorrentes do processo de desregulamentação. Este fato pode ser evidenciado por meio da suspensão do Acordo Internacional do Café (AIC) e, no plano interno, pela extinção do Instituto Brasileiro do Café (GIESBRECHT et al., 2014).

Saes (1995) relata que dois fatores contribuíram para o processo de desregulamentação do café no Brasil. O primeiro está relacionado à crise fiscal do Estado, caracterizado pelo desequilíbrio macroeconômico, culminando com o fim de um longo período de intervenção do Estado na economia brasileira. Ademais, as políticas neoliberais aceleraram este processo de desregulamentação. O segundo diz respeito à própria política cafeeira, cuja valorização dos preços do café, ao longo dos anos, culminou com o surgimento de uma crise no setor.

Conforme ressalta Zylbersztajn (2001), o processo de desregulamentação provocou uma nova tendência para o tradicional setor cafeeiro, pois muitos produtores passaram a investir em novas estratégias, entre elas, a valorização de produtos diferenciados. 
Neste contexto, inserem-se os cafés especiais, cujo conceito está fortemente vinculado ao prazer proporcionado pela bebida. Destacam-se por certo atributo ligado ao produto, ao processo de produção ou ao serviço a ele associado. Têm características diferenciadas, como a qualidade superior da bebida, o modo como são cultivados e colhidos, aspecto do grão, tipo de preparo, procedência dos plantios, variedades, história, entre outras. Esse destaque pode também ser atribuído à sustentabilidade ambiental, econômica e social, aproximando os elos da cadeia (ZYLBERSZTAJN, 2001; SAES E SPERS, 2006). De acordo com essa abordagem, Alves et al. (2011, p. 2) afirmam:

O café é uma bebida que se expressa diferentemente em função do local de plantio. É essencialmente um produto de terroir, ou seja, influenciado diretamente pelos aspectos ambientais, tanto os naturais quanto os humanos. Os diferentes métodos de cultivo, bem como as diferentes técnicas de colheita e de secagem, que refletem o 'saber fazer' local e as condições particulares de clima, solo e relevo, associados às características genéticas das diferentes variedades, criam a identidade da bebida [...].

Na concepção de Paiva (2010), a análise sensorial da bebida é o modo mais utilizado para se identificar a qualidade do café. De acordo com Mascarenhas e Bernardes (2016), a Specialty Coffee Association of America (SCAA) é a principal instituição que determina padrões de qualidade para os cafés especiais. Sob essa ótica, Barbosa (2018) ressalta que a referida instituição realiza a avaliação sensorial do café por meio de um protocolo específico. Nesse processo, considera-se a amostra, moagem e o nível da torra. Ademais, por meio de um formulário avaliam-se os seguintes atributos: aroma/fragrância, uniformidade, ausência de defeitos, limpeza da xícara, doçura, sabor, acidez, corpo, permanência do gosto, equilíbrio e avaliação global. Assim, os critérios de classificação dos cafés são baseados numa escala de pontos divididos em 10 características, cada uma valendo até 10 pontos. Os cafés são classificados como especiais quando a soma desses quesitos for maior que 80 pontos.

\section{METODOLOGIA}

O presente artigo foi desenvolvido na perspectiva de uma pesquisa descritiva de cunho qualitativo, uma vez que o levantamento de dados teve como base a percepção dos atores locais acerca das Indicações Geográficas como ferramenta para o desenvolvimento do território. De acordo com Cervo, Bervian e Silva (2007, p. 61), a pesquisa descritiva "busca conhecer as diversas situações e relações que ocorrem na vida social, política, econômica e demais aspectos do comportamento humano [...]".

Foi utilizada também a pesquisa bibliográfica e documental, na qual se analisaram os documentos do pedido de Indicação de Procedência elaborado e encaminhado pela Associação dos Produtores de Café da Mantiqueira (APROCAM) ao INPI.

A pesquisa de campo foi realizada entre os meses de fevereiro e julho de 2018. Para a escolha da amostra, considerou-se que o território a ser pesquisado deveria ter predominância de produtores e comerciantes de café que usufruem do registro de IG. Em contato com a Associação dos Produtores de Café, verificou-se que, no município de Carmo de Minas, concentra-se o maior número de produtores que utilizam o selo da IG. Diante disso, foram identificados como atores relevantes a Associação dos Produtores de Café da Mantiqueira (APROCAM), a Cooperativa Regional dos Cafeicultores do Vale do Rio Verde (COCARIVE), os cafeicultores, como produtores, profissionais ligados ao ramo de café, e o SEBRAE-MG. Desse modo, foi efetuado um total de 11 
entrevistas, sendo dois representantes da APROCAM, dois da COCARIVE, um do SEBRAE e seis produtores de café.

As entrevistas foram individuais e em profundidade, a partir de um roteiro semiestruturado, com duração entre 30 e 60 minutos. Todas as entrevistas foram gravadas e transcritas. Os dados coletados foram tratados por meio de procedimentos de análise de conteúdo, em que o tratamento envolve a codificação e a apresentação de forma mais estruturada dos dados levantados (VERGARA, 2014). Para Appolinário (2011, p. 161), o método de análise "denominado 'análise de conteúdo' tem por finalidade básica a busca do significado de materiais textuais, sejam eles artigos de revistas [...] transcrição de entrevistas realizadas com sujeitos, individual ou coletivamente".

\section{RESULTADOS E DISCUSSÕES}

\subsection{Caracterização do território}

Historicamente, a cultura do café na região da Mantiqueira iniciou-se por volta de 1848. Acreditava-se que o local não seria propício para a plantação de café, em função da ocorrência de névoas e geadas típicas de regiões montanhosas, sendo comum no inverno a temperatura atingir $0^{\circ} \mathrm{C}$ (GIESBRECHT et al., 2014).

No entanto, com o decorrer dos anos, a região da Serra da Mantiqueira de Minas Gerais vem apresentando condições ambientais propícias à produção de cafés de alta qualidade. Tem padrão climático ideal para o cultivo de café, com temperatura média anual em torno de $19^{\circ} \mathrm{C}$, isto porque o café da espécie arábica necessita de temperaturas entre $18^{\circ} \mathrm{C}$ e $22^{\circ} \mathrm{C}$ para que apresente um bom desempenho.

Ademais, a região configura-se por uma boa distribuição de chuvas ao longo do ano, com precipitação média anual de 2.000 mm, favorecendo as fases de floração, maturação e colheita, sendo a colheita realizada entre maio e agosto, período de baixa pluviosidade. Alves et al. (2011) salientam que o clima "caracteriza-se por uma sazonalidade bem definida, com duas estações claramente distintas, um verão úmido e quente e um inverno seco e ameno, e outras duas de transição, o outono e a primavera" (ALVES et al., 2011, p. 7).

A altitude é um outro fator extremamente favorável ao desenvolvimento do café. De acordo com o processo de pedido da Indicação de Procedência enviado pela Associação dos Produtores de Café da Mantiqueira (APROCAM) ao INPI, a altitude para produção deve estar entre 850 e 1.500 metros acima do nível do mar. Como destacam Alves et al. (2011), nessa região, o clima e a altitude são muito importantes para a maturação dos cafés, isto em função da disponibilidade de água, temperatura e luz.

Além dos fatores ambientais, geográficos, da espécie e de suas variedades, destaca-se o sistema de produção e colheita, em que são adotados cuidados quanto à colheita, lavagem dos grãos, separação, descascamento, secagem e beneficiamento. O processo pós-colheita engloba as técnicas do café natural: o café é secado de modo integral, naturalmente, sendo utilizada a forma mais antiga e tradicional; café cereja descascado: ocorre a retirada da casca externa por meio de máquinas; café cereja descascado desmucilado: parecido com o cereja descascado, no entanto retira-se por meio de máquinas a mucilagem existente entre o pergaminho e a casca externa. Tais cuidados, aliados às características ambientais da região, proporcionam cafés com propriedades diferenciadas, com qualidade e, portanto, especiais (INPI, 2007). 


\subsection{A Indicação GEOGRÁFICA do café da Serra da Mantiqueira de Minas Gerais}

Atualmente, existem sete Indicações Geográficas para o café no Brasil. O café da Região do Cerrado Mineiro foi o primeiro a obter o registro de Indicação de Procedência no ano de 2005 e, em 2013, alcançou o registro de Denominação de Origem. Em 2011, foi a vez do café da Região da Serra da Mantiqueira de Minas Gerais receber o registro de IP. Também obtiveram registro de IP os seguintes cafés: Norte Pioneiro do Paraná (2012), Alto Mogiana (2013), Região do Pinhal (2016), Oeste da Bahia (2019) e Matas de Minas (2019) (INPI, [s.d.]).

Diante do reconhecimento obtido por meio dos concursos de qualidade, a Associação dos Produtores de Café percebeu que havia necessidade de mostrar que o café da região continha elementos que o tornavam diferenciado. Por meio dos concursos, os cafés da Mantiqueira ganhavam prêmios e se destacavam como oriundos da região da Mantiqueira. Diante disso, o pedido de registro do café da região da Mantiqueira de Minas foi requerido em 3 de outubro de 2007, na espécie de Indicação de Procedência, tendo como requisitante a Associação dos Produtores de Café da Mantiqueira (APROCAM), sendo sua concessão obtida em 31 de maio de 2011.

Segundo dados da Mantiqueira de Minas (2019), a área geográfica demarcada pela Indicação de Procedência compreende, atualmente, 22 municípios, sendo eles: Baependi, Brazópolis, Cachoeira de Minas, Cambuquira, Campanha, Carmo de Minas, Caxambu, Conceição das Pedras, Conceição do Rio Verde, Cristina, Dom Viçoso, Heliodora, Jesuânia, Lambari, Natércia, Paraisópolis, Olímpio Noronha, Pedralva, Pouso Alto, Santa Rita do Sapucaí, São Lourenço e Soledade de Minas, conforme Figura 1.

Figura 1 - Mapa dos municípios que fazem parte da Indicação de Procedência do café da Região da Serra da Mantiqueira de Minas Gerais

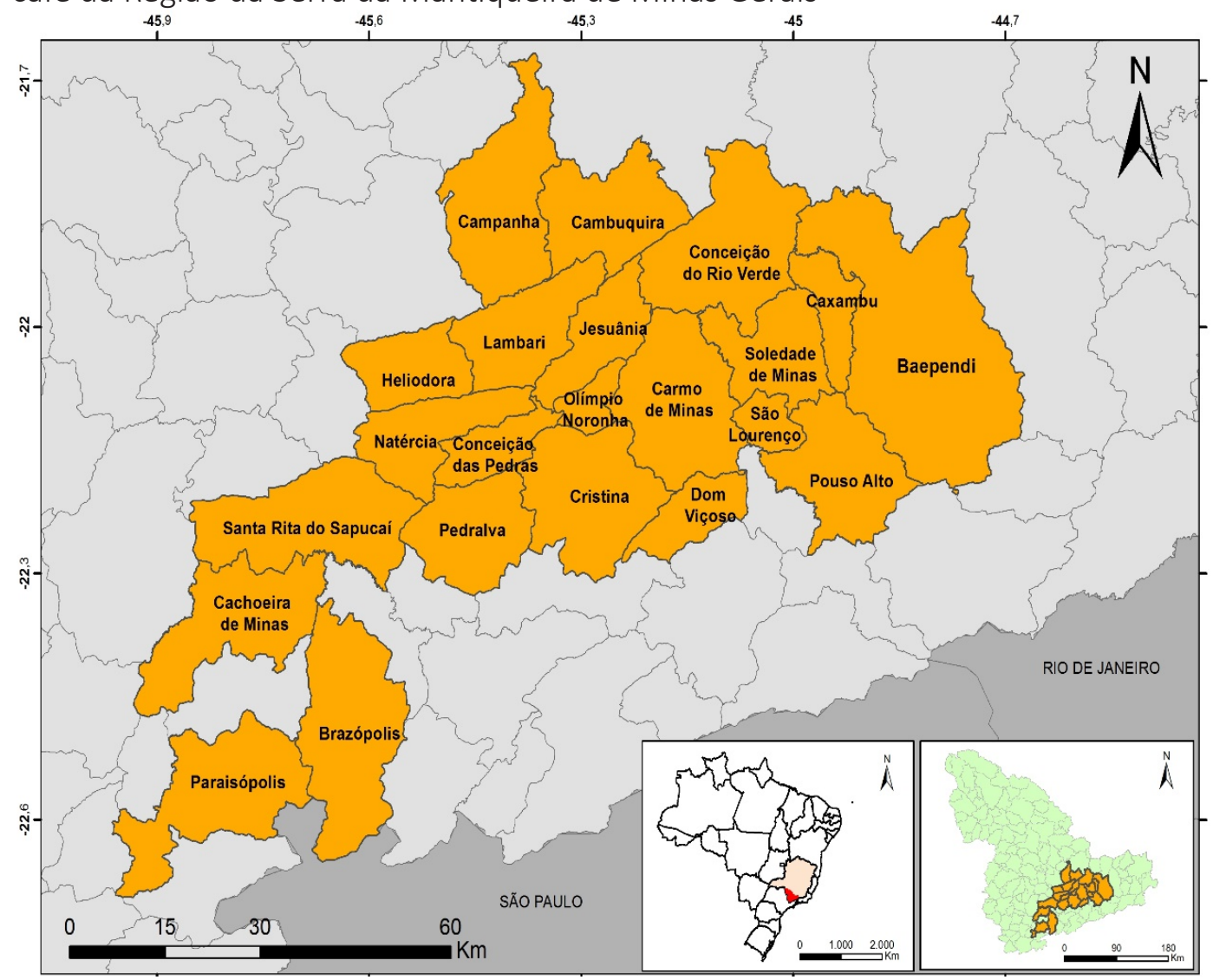

Fonte: Mantiqueira de Minas (2019). 
A Associação dos Produtores de Café da Mantiqueira (APROCAM) é a entidade gestora da Indicação de Procedência, sendo composta pelas seguintes entidades: Cooperativa Regional dos Cafeicultores do Vale do Rio Verde Ltda. (COCARIVE), Cooperativa Regional Agropecuária de Santa Rita do Sapucaí (COOPERRITA), Cooperativa Agropecuária do Vale do Sapucaí (COOPERVASS), Sindicato dos Produtores Rurais de Carmo de Minas e Sindicato dos Produtores Rurais de Santa Rita do Sapucaí (MANTIQUEIRA DE MINAS, s.d.).

Cabe ressaltar que os produtores, ao utilizarem o selo de Indicação de Procedência do café da Mantiqueira, devem seguir algumas regras. Entre elas: a) a propriedade deve estar localizada dentro da região demarcada; b) necessita ser associado de cooperativas ou sindicatos que fazem parte do Conselho da Mantiqueira; c) os cafés devem ser depositados em armazéns da COOPERRITA, COCARIVE ou COOPERVASS; d) necessita de uma pontuação mínima de 83 (metodologia SCAA ${ }^{3}$ ).

\subsection{Percepções dos principais atores envolvidos na Indicação Geográfica do Café da Serra da Mantiqueira de Minas Gerais}

No território da Mantiqueira, foram entrevistados onze atores locais, com idade entre 22 e 70 anos e com grau de escolaridade com variação de nível médio à pós-graduação. Dos onze entrevistados, nove são do gênero masculino e dois pertencem ao gênero feminino. Em sua maioria, são indivíduos que têm experiência com a cultura do café.

De acordo com a Tabela 1, entre os seis produtores de café entrevistados, dois estão em famílias que há mais de cem anos se dedicam ao cultivo do café, demostrando a tradição secular da produção. Quanto à área e ao uso de mão de obra no cultivo do café, verifica-se que o produtor com área de cinco hectares (ha) utiliza somente mão de obra familiar, sendo considerado, de acordo com a Lei n. 11.326, de junho de 2006, agricultor familiar. Já os demais, com área superior a 40 ha, utilizam mão de obra contratada e, portanto, não se enquadram na categoria de agricultor familiar.

Tabela 1 - Caracterização dos produtores de café

\begin{tabular}{cccc}
\hline Código* & $\begin{array}{c}\text { Tempo em que a família } \\
\text { atua na produção de café }\end{array}$ & $\begin{array}{c}\text { Tamanho da área destinada à } \\
\text { produção de café }\end{array}$ & Tipo de mão de obra \\
\hline E2 & Mais de 100 anos & $150 \mathrm{ha}$ & Contratada \\
E3 & 28 anos & $5 \mathrm{ha}$ & Familiar \\
E4 & 60 anos & $46 \mathrm{ha}$ & Contratada \\
E5 & 39 anos & $65 \mathrm{ha}$ & Contratada \\
E9 & Mais de 100 anos & $500 \mathrm{ha}$ & Contratada \\
\hline E10 & 90 anos & $15 \mathrm{ha}$ & Contratada \\
\hline
\end{tabular}

*Nota: no intuito de evitar a identificação dos entrevistados, foi utilizada tabela com códigos.

Fonte: Dados da pesquisa (2018).

De acordo com os produtores de café e um representante da APROCAM, os principais benefícios oriundos da região, e que possibilitam a diferenciação do café, estão relacionados ao clima, altitude, atributos humanos ligados à colheita e pós-colheita, além do solo e do regime pluviométrico.

\footnotetext{
${ }^{3}$ As normas para classificação de cafés da SCAA são fundamentadas em uma escala que varia de 65 a 100 pontos. São avaliadas 10 características, cada uma delas com valor de até 10 pontos, sendo elas: aroma, uniformidade, limpeza da xícara, doçura, sabor, acidez, corpo, permanência do gosto, equilíbrio e global. Ademais, consideram-se os defeitos, o ponto da torra e o grau de intensidade em xícara (MASCARENHAS; BERNARDES, 2016).
} 
Nesse contexto, pode-se afirmar que a região da Serra da Mantiqueira de Minas Gerais apresenta elementos que tornam o território diferenciado, o que confirma a teoria de Pecqueur (2005) de que os atores locais devem buscar os recursos (tangíveis e intangíveis) próprios do território que permitam a diferenciação de seus produtos. Sob esta ótica, e de acordo com as afirmações de Saquet e Briskievicz (2009), é possível considerar a hipótese de que o território da Mantiqueira dispõe de recursos específicos e não transferíveis de um local para outro e, desse modo, tem o potencial de gerar desenvolvimento.

No que tange ao café especial, conforme enfatizado no referencial teórico, é concebível indicar o grau de qualidade do café por meio da metodologia SCAA. Diante disso, a qualidade é quantificada por meio de uma escala que vai de zero a cem pontos, sendo os cafés com pontuação acima de 80 considerado como café especial.

Tendo por base a Tabela 2, observa-se que, ao longo dos anos, mais especificamente a partir de 2011, houve uma mudança na qualidade dos cafés da Serra da Mantiqueira de Minas Gerais.

Tabela 2 - Análise sensorial do café da Serra da Mantiqueira de Minas Gerais. Período: 2011 a 2018

\begin{tabular}{ccccc}
\hline Período & Até $\mathbf{7 9}$ pontos & $\mathbf{8 0}$ a $\mathbf{8 3}$ pontos & $\mathbf{8 4}$ a $\mathbf{8 6}$ pontos & Acima de $\mathbf{8 7}$ pontos \\
\hline $2011 / 2012$ & $56,74 \%$ & $24,17 \%$ & $9,96 \%$ & $9,13 \%$ \\
$2012 / 2013$ & $55,30 \%$ & $21,10 \%$ & $13,00 \%$ & $10,57 \%$ \\
$2013 / 2014$ & $61,20 \%$ & $19,82 \%$ & $11,81 \%$ & $7,17 \%$ \\
$2014 / 2015$ & $56,30 \%$ & $25,00 \%$ & $14,45 \%$ & $4,25 \%$ \\
$2015 / 2016$ & $30,80 \%$ & $27,30 \%$ & $27,20 \%$ & $14,70 \%$ \\
$2016 / 2017$ & $23,38 \%$ & $32,50 \%$ & $31,13 \%$ & $12,99 \%$ \\
\hline $2017 / 2018$ & $18,50 \%$ & $30,95 \%$ & $35,07 \%$ & $15,47 \%$ \\
\hline
\end{tabular}

Fonte: dados da pesquisa (2018).

De 2011 a 2018, houve uma redução na quantidade de cafés com pontuação até 79, passando de $56,74 \%$ para $18,50 \%$. Por outro lado, houve uma elevação da quantidade de cafés com pontuação acima de 80 . Desse modo, ao compararmos a pontuação dos cafés entre 2011/12 com os anos 2017/18, nota-se uma mudança significativa na qualidade do produto. No período que compreende os anos de 2017/18, os cafés com pontuação entre 84 e 86 estão entre os produzidos em maior quantidade, representando 35,05\% do total. Ademais, os cafés com pontuação acima de 87 vêm crescendo gradualmente ao longo dos anos.

Vale ressaltar que o registro de IG foi concedido em 2011 e, naquele momento, exigia-se pontuação mínima igual a 80 para usufruir do selo de Indicação de Procedência. Atualmente, a pontuação mínima estipulada para uso do selo é de 83 pontos. Neste contexto, pode-se indicar que a mudança de 80 para 83 pontos só foi possível em virtude das contínuas melhorias no processo de produção, juntamente das inovações proporcionadas pelos agentes envolvidos na produção, classificação e comercialização do café. Entre as melhorias, é válido mencionar a aquisição de máquinas de última geração pelos produtores e cooperativas; a participação dos produtores em concursos de qualidade do café desde os anos 2000; e a capacitação direcionada a produtores para aprimoramento da qualidade e para os demais agentes envolvidos no rebeneficiamento e na avaliação da qualidade do café na cooperativa. 


\subsection{O papel desempenhado pelas cooperativas no processo de desenvolvimento}

As cooperativas realizam um papel relevante na região da Mantiqueira, pois participam de toda a cadeia do café. A COCARIVE, cooperativa localizada em Carmo de Minas, vende insumos aos associados por meio de uma loja, além de possibilitar rebeneficiamento, armazenagem, avaliação da qualidade e comercialização do café.

As cooperativas são as principais responsáveis pela comercialização dos cafés com registro da IG. Sob esta ótica, todo o café especial, para ter reconhecimento da qualidade, deve passar pela cooperativa. Conforme exposto no Gráfico 1, ao compararmos as vendas de café em 2012, que era de 960 sacas, com o período 2017/18, no qual foram vendidas 50.120 sacas de café especial, constata-se que o volume exportado vem crescendo de forma expressiva.

Gráfico 1 - Volume de café especial exportado entre 2012 e 2018 pela COCARIVE (Sacas de $60 \mathrm{~kg}$ )

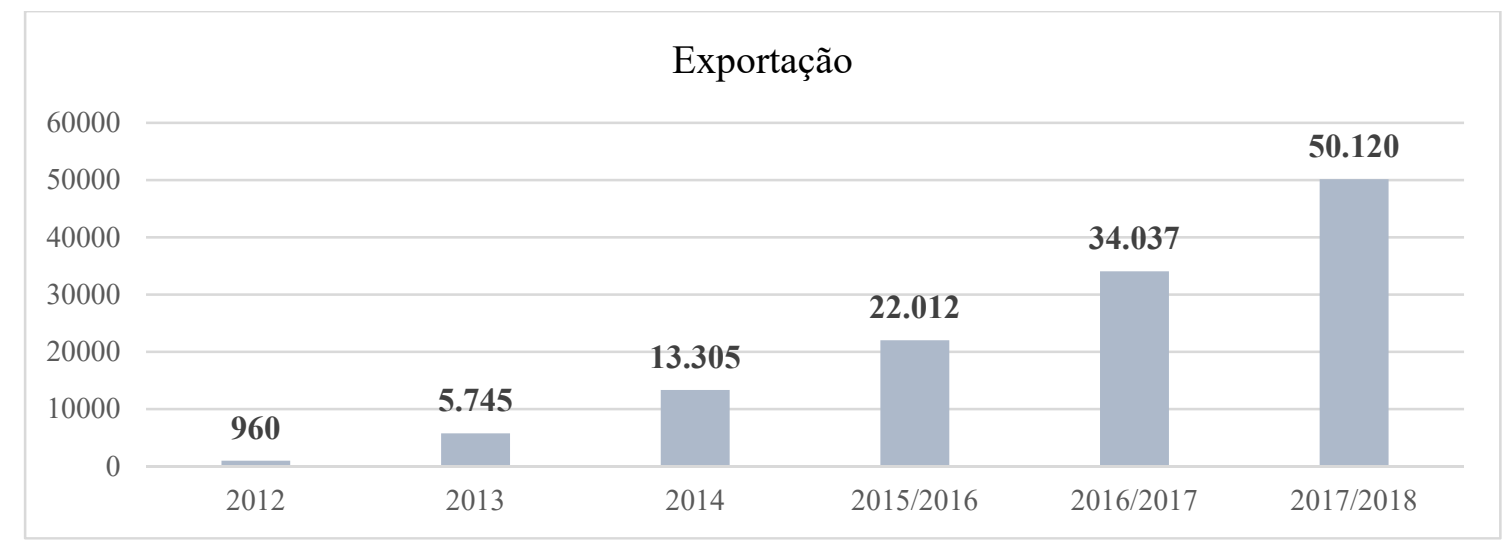

Fonte: Dados da pesquisa (2018).

Do mesmo modo, na análise dos preços dos cafés especiais vendidos no mercado externo, observa-se que os valores se mantêm em patamares elevados desde 2012. De acordo com o Gráfico 2, o ano de 2016 registrou o maior valor do preço da saca de café, equivalente a cerca de R\$905,93 (novecentos e cinco reais e noventa e três centavos, preço médio). Já no ano de 2017, o valor correspondeu a $\mathrm{R} \$ 792,51$ (setecentos e noventa e dois reais e cinquenta e um centavos).

Gráfico 2 - Preço médio bruto de exportação de café especial entre 2012 e 2017

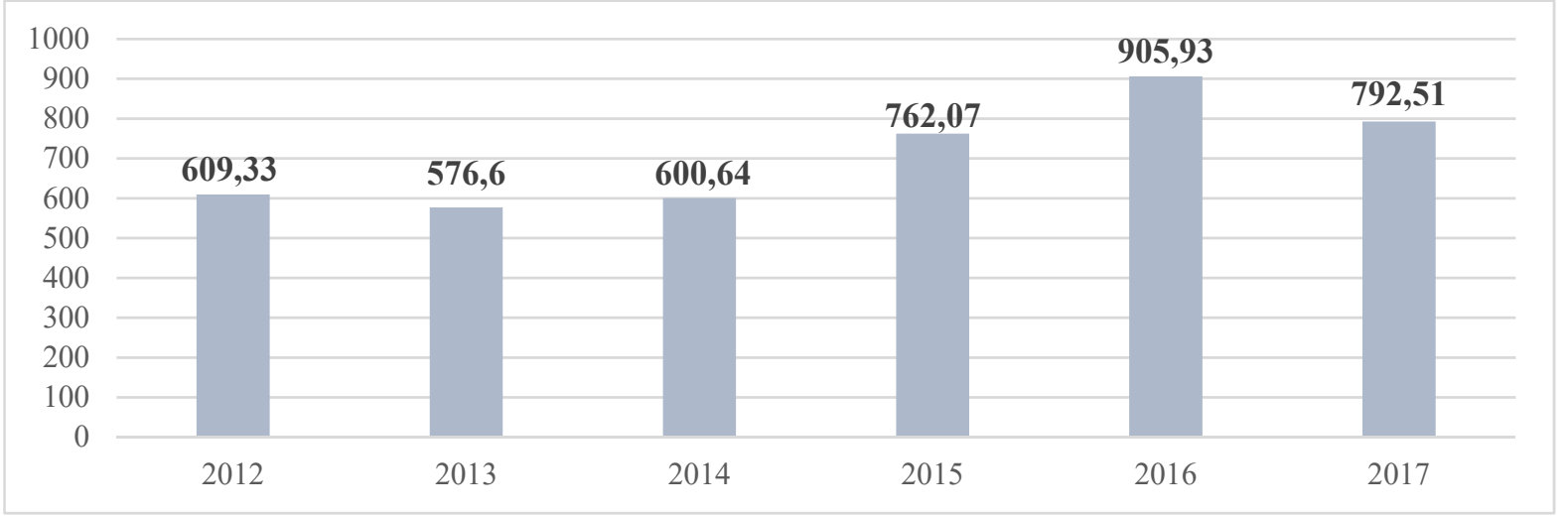

Fonte: Dados da pesquisa (2018). 
Neste contexto, pode-se afirmar que a IG do café da Serra da Mantiqueira de Minas Gerais constitui uma ferramenta que contribui para a elevação do volume exportado, do preço, bem como da expansão de países de destino das exportações.

Esses dados vão ao encontro da pesquisa realizada por Vandecandelaere et al. (2018), na qual afirmam que, nos nove casos estudados de IG no mundo, apenas no chá Darjeeling, da Índia, não se verificou aumento do volume de produção. Quanto aos preços, em todos os casos estudados observou-se que a IG eleva de modo considerável o preço do produto final ou da matéria-prima. Tal resultado independe do tipo de produto ou da região de origem. No que se refere à diversificação de mercado, todas as nove IGs analisadas obtiveram aumento do número de países de destino de suas exportações.

Conforme apontado no referencial teórico, existem discussões que assinalam o potencial das IGs enquanto ferramenta de desenvolvimento territorial. Diante disso, nove entrevistados afirmaram que a Indicação Geográfica Protegida (café especial e certificação de origem) possibilitam: a inserção do produto no mercado interno e externo; aumento da renda dos produtores; melhora na qualidade de vida dos produtores e dos empregados; preservação do saber-fazer; e aumento do interesse dos filhos, parentes e demais familiares em continuar no negócio do café. Oito entrevistados responderam que os cafés especiais e a certificação de origem ocasionam um incremento no turismo na região. Sete dos respondentes acreditam que geram empregos; e seis deles concordam que a IG promove a fixação da população na zona rural.

Diante dos dados evidenciados por meio das entrevistas, pode-se afirmar que os benefícios e as vantagens procedentes da Indicação Geográfica têm o potencial de promover o desenvolvimento, pois, conforme ressalta Velloso (2008), "embora as Indicações Geográficas não tenham sido concebidas para promover o desenvolvimento territorial, elas podem servir como ferramenta para tal" (VELLOSO, 2008, p. 44).

Assim, quando se tem um trabalho bem estruturado de construção da Indicação Geográfica, "há um efeito transbordamento das positividades que vão além dos produtores na medida em que potencializa o desenvolvimento socioeconômico do território com ganhos na valorização do patrimônio cultural e nas atividades turísticas" (GUEDES, 2014, p. 413).

Neste contexto, observou-se que o turismo vinculado aos cafés especiais é uma tendência que vem se destacando na região da Mantiqueira. Em Carmo de Minas, município reconhecido pela tradição de se produzir excelentes cafés, os turistas podem usufruir de visitas a fazendas produtoras. Entre as propriedades, destaca-se a Fazenda Sertão, que há mais de cem anos dedicase ao cultivo do café, sendo o passeio até a fazenda proporcionado pela Rota do Café Especial. Um outro evento, também promovido pela Rota do Café Especial, denominado "Do pé à xícara de Balão", possibilita ao turista apreciar os cafezais por meio de um balão.

Outros eventos vinculados à figura do café especial têm sido desenvolvidos nos últimos anos, visando fortalecer o turismo na região. Em 2016, uma parceria entre o Campus Avançado Carmo de Minas, do Instituto Federal do Sul de Minas (IFSULDEMINAS), São Lourenço Convention \& Visitors Bureau e o Senac Minas promoveu o V Festival Gastronômico Degusta 2016 - "Comer Café", que teve como foco promover a gastronomia e o turismo na região utilizando o café como ingrediente principal. Outro evento envolvendo os cafés foi o Festival do Café Especial, promovido em Carmo de Minas, em 2017. Com o mesmo objetivo, em 2018, o município de Cristina organizou o festival intitulado Festival de Café com Música. 
Neste viés, cabe ressaltar que a região de estudo, especialmente São Lourenço, com uma rede hoteleira diversificada e consolidada, é um local que recebe visitantes durante todo o ano, em virtude das atrações turísticas vinculadas, de maneira especial, às estâncias hidrominerais. Neste cenário, a reputação e a tradição dos cafés da Mantiqueira têm o potencial de incrementar o turismo, favorecendo, desse modo, pousadas, hotéis, restaurantes, lojas, entre outros.

\section{CONCLUSÕES}

Nesta pesquisa, verificou-se que a obtenção do registro de Indicação Geográfica e as contínuas melhorias no processo de produção do café, proporcionadas pelos produtores e pelas cooperativas, possibilitam aos pequenos e médios produtores rurais ampliar as vendas e alcançar, cada vez mais, mercados mais sofisticados, principalmente no setor externo, pelo fato de produzirem cafés de alta qualidade e mundialmente reconhecidos, com preços diferenciados.

Ademais, a produção de cafés especiais com a certificação de origem, conforme apontado na pesquisa, possibilita: a geração de empregos, preservação do saber-fazer, melhoria na qualidade de vida dos produtores e empregados, aumento do interesse dos filhos e parentes em continuar na produção de cafés e, por fim, incremento do turismo na região. Neste contexto, deve-se ressaltar que a região delimitada pela Indicação Geográfica tem uma aptidão para o turismo, pois compreende os principais municípios do Circuito das Águas, como Caxambu, São Lourenço, Lambari, Cambuquira, entre outros. Diante disso, pode-se afirmar que a IG é uma ferramenta que contribui para o desenvolvimento local, especialmente nos municípios de Carmo de Minas e em São Lourenço.

Entre as limitações da pesquisa, é válido mencionar a dificuldade de acesso aos entrevistados, pois grande parte deles residem em áreas rurais. Considerando possibilidades de novas pesquisas sobre este tema, sugere-se analisar a influência da IG com um maior número de entrevistados e em outros municípios inseridos no território da Mantiqueira de Minas Gerais.

\section{REFERÊNCIAS}

ALVES, H. M. R.; VOLPATO, M. M. L.; VIEIRA, T. G. C.; BORÉM, F. M.; BARBOSA, J. N. Características ambientais e qualidade da bebida dos cafés do estado de Minas Gerais. Informe Agropecuário, Belo Horizonte, v. 32, n. 261, p. 18-29, mar./abr. 2011.

APPOLINÁRIO, F. Metodologia da Ciência: filosofia e prática da pesquisa. São Paulo: Cengage Learning, 2011. BARBOSA, I. P. Avaliação de cultivares de Coffea arabica para cafés especiais na região das Matas de Minas. 2018. 88 f. Dissertação (Mestrado em Genética e Melhoramento) - Universidade Federal de Viçosa, Viçosa, MG, 2018.

BELAS, C. A. Artesanato e indicação geográfica: uma nova agenda de pesquisa e desenvolvimento nos países emergentes. In: NIEDERLE, P. A. (Org.). Indicações Geográficas: qualidade e origem nos mercados alimentares. Porto Alegre: UFRGS, 2013.

BRASIL. Lei n. 9.279, de 14 de maio de 1996. Regula direitos e obrigações relativos à propriedade industrial. Diário Oficial da União, Brasília-DF, 15 de maio 1996. Disponível em: http://pesquisa.in.gov.br/imprensa/jsp/ visualiza/index.jsp?data=15/05/1996\&jornal=1\&pagina=11\&totalArquivos=136. Acesso em: 17 ago. 2019.

BRUCH, K. L. A legislação brasileira sobre Indicações Geográficas em face das experiências internacionais. In: NIEDERLE, P. A. (Org.). Indicações Geográficas: qualidade e origem nos mercados alimentares. Porto Alegre: UFRGS, 2013. 
CARRIÈRE, J. P; CAZELLA, A. A. Abordagem introdutória ao conceito de desenvolvimento territorial. Eisforia, Florianópolis, v. 4, n. especial, p. 23-47, dez. 2006.

CERDAN, C. Indicações Geográficas e estratégias de desenvolvimento territorial. In: NIEDERLE, P. A. (Org.). Indicações Geográficas: qualidade e origem nos mercados alimentares. Porto Alegre: UFRGS, 2013.

CERVO, A. L.; BERVIAN, P. A.; SILVA, R. da. Metodologia científica. 6. ed. São Paulo: Pearson Prentice Hall, 2007.

CHAMBERLIN, E. H. Diferenciación del producto: competencia monopólica. In: CHAMBERLIN, E. H. Teoría de la competencia monopólica. México: Fundo de Cultura, 1956.

CHAMPEDRONE, M. La valorización de la tipicidad cultural y territorial de productos mediante certificaciones en países de América Latina. In: FROEHLICH, J. M. (Org.). Desenvolvimento territorial: produção, identidade e consumo. ljuí: UNIJUÍ, 2012.

CONSELHO DOS EXPORTADORES DE CAFÉ DO BRASIL [CECAFÉ]. Produção. Cecafé, São Paulo, [s.d.]. Disponível em: https://www.cecafe.com.br/sobre-o-cafe/producao/. Acesso em: 10 out. 2018.

GIESBRECHT, H. O.; MINAS, R. B. A.; GONÇALVES, M. F. W.; SCHWANKE, F. H. Indicações geográficas brasileiras - café. Brasília: SEBRAE/INPI, 2014. Disponível em: http://www.bibliotecas.sebrae.com.br/ chronus/ARQUIVOS_CHRONUS/bds/bds.nsf/c7980384f923f343310b3d7ca0e5cb3b/\$File/5127.pdf. Acesso em: 18 jul. 2018.

GUEDES, C. A. M.; SILVA, R. Agri-food geographical indications, policies, and social management: Argentina, Brazil, and the Spanish experience in the European context. Análise Social, Lisboa, v. XLIX (2), n. 211, p. 408-29, 2014.

INSTITUTO NACIONAL DE PROPRIEDADE INDUSTRIAL [INPI]. Processo de Indicação de Procedência para a Região da Serra da Mantiqueira de Minas Gerais: processo n. IG200704, de 3 de outubro de 2007. (Requerente: Associação dos Produtores de Café da Serra da Mantiqueira). Rio de Janeiro: INPI, 2007.

INSTITUTO NACIONAL DE PROPRIEDADE INDUSTRIAL [INPI]. Indicações Geográficas registradas. INPI, Rio de Janeiro, [s.d.]. Disponível em: http://www.inpi.gov.br/menu-servicos/indicacao-geografica/pedidosde-indicacao-geografica-no-brasil. Acesso em: 18 ago. 2019.

LÓPEZ NETTO, A.; ASSIS, R. L.; GUEDES, C. A. M.; AQUINO, A. M. Denominações territoriais agroalimentares: experiências da União Europeia e do Mercosul para o desenvolvimento territorial dos ambientes de montanha. Estudos Sociedade e Agricultura, Rio de Janeiro, v. 23, n. 2, p. 298-93, 2015.

MANTIQUEIRA DE MINAS. Os 22 municípios que formam a área demarcada. Carmo de Minas: Associação dos Produtores de Café, 2019.

MANTIQUEIRA DE MINAS. Como estamos organizados. Carmo de Minas: Associação dos produtores de Café, [s.d.]. Disponível em: http://www.mantiqueirademinas.com.br/organization. Acesso em: 2 set. 2018.

MASCARENHAS, G. C. C.; BERNARDES, R. M. A (R)evolução dos cafés: o resgate da qualidade a partir das origens. In: WILKINSON, P.; NIEDERLE, A.; MASCARENHAS, G. C. C. (Org.). O sabor da origem: produtos territorializados na nova dinâmica dos mercados alimentares. Porto Alegre: Escritos do Brasil, 2016.

NIEDERLE, P. A. Controvérsias sobre a noção de Indicações Geográficas enquanto instrumento de desenvolvimento territorial: a experiência do Vale dos Vinhedos em questão. In: SOCIEDADE BRASILEIRA DE ECONOMIA, ADMINISTRAÇÃO E SOCIOLOGIA RURAL, 47., 26 a 30 jul., 2009, Porto Alegre. Anais [...]. Porto Alegre: SOBER, 2009. 
PAIVA, E. F. F. Avaliação sensorial de cafés especiais: um enfoque multivariado. 2010. 99 f. Tese (Doutorado em Ciência dos Alimentos) - Universidade Federal de Lavras, Lavras, MG, 2010.

PECQUEUR, B. O desenvolvimento territorial: uma nova abordagem dos processos de desenvolvimento para as economias do sul. Raízes, Campina Grande, v. 24, n. 1/2, p. 10-22, jan./dez. 2005.

PEREIRA, M. E. B. G.; LOURENZANI, A. E. B. S.; WATANABE, K. Indicações Geográficas como estratégia de desenvolvimento: o caso do Norte Pioneiro do Paraná. Interações, Campo Grande, v. 19, n. 3, p. 515-28, jul./set. 2018.

SAES, M. S. M. A racionalidade econômica da regulamentação no mercado brasileiro de café. 1995. 163 f. Tese (Doutorado em Economia) - Faculdade de Economia, Administração e Contabilidade, Universidade de São Paulo, São Paulo, SP, 1995.

SAES, M. S. M.; SPERS, E. E. Percepção do consumidor sobre os atributos de diferenciação no segmento rural: café no mercado interno. Organizações Rurais \& Agroindustriais, Lavras, v. 8, n. 3, p. 354-67, 2006.

SAQUET, M. A. Abordagens e concepções de território. 3. ed. São Paulo: Outras Expressões, 2013.

SAQUET, M. A.; BRISKIEVICZ, M. Territorialidade e identidade: um patrimônio no desenvolvimento territorial. Caderno Prudentino de Geografia, Cidade, v. 1, n. 31, p. 3-16, 2009.

VALENTE, M. E. R.; PEREZ, R.; RAMOS, A. M.; CHAVES, J. B. P. Indicação Geográfica de alimentos e bebidas no Brasil e na União Europeia. Ciência Rural, Santa Maria, v. 42, n. 3, p. 551-58, mar. 2012.

VANDECANDELAERE, E.; TEYSSIER, C.; JEANNEAUX, P.; FOURNIER, S.; BEUCHERIE, O. Strengthening sustainable food systems through geographical indication: an analysis of economic impacts. European Bank for Reconstruction and Development (EBRD), 2018. p. 3-16.

VELLOSO, C. Q. Indicação Geográfica e desenvolvimento territorial sustentável: a atuação dos atores sociais nas dinâmicas de desenvolvimento territorial a partir da ligação do produto ao território (um estudo de caso em Urussanga, SC). 2008. 166 f. Dissertação (Mestrado em Agroecossistemas) - Centro de Ciências Agrárias, Universidade Federal de Santa Catarina, Florianópolis, 2008.

VERGARA, S. C. Projetos e relatórios de pesquisa em administração. 15. ed. São Paulo: Atlas, 2014.

ZYLBERSZTAJN, D.; FARINA, E. M. M. Q.; SAES, M. S. M.; SOUZA, M. C. M. Diagnóstico sobre o sistema agroindustrial de cafés especiais e qualidade superior do estado de Minas Gerais. São Paulo: Sebrae, 2001.

\section{Sobre os autores:}

Maria Helena Facirolli Sobrinho: Doutora em Políticas Públicas pela Universidade Federal Rural do Rio de Janeiro. Professora Adjunta C3 do Departamento de Ciências Econômicas e Exatas do Instituto Três Rios, Universidade Federal Rural do Rio de Janeiro (UFRRJ). E-mail: mhfacirolli@gmail.com, Orcid: http://orcid.org/0000-0001-7018-1212

Cezar Augusto Miranda Guedes: Doutor pela Escola de Administração de Empresas de São Paulo da Fundação Getúlio Vargas. Professor Titular do Programa de Pós-Graduação em Ciência, Tecnologia e Inovação em Agropecuária da Universidade Federal Rural do Rio de Janeiro (PPGCTIA).

E-mail: cezar.eco@gmail.com, Orcid: http://orcid.org/0000-0003-2287-3948 
Maria Cristina Drumond e Castro: Doutora em Políticas Públicas pela Universidade Federal Rural do Rio de Janeiro. Professora Adjunta Classe C Nível II da Universidade Federal Rural do Rio de Janeiro (UFRRJ), Instituto Três Rios (ITR). Professora do Quadro Permanente do Programa Mestrado Profissional em Gestão \& Estratégia da UFRRJ. E-mail: cristinadrumond2010@gmail.com, Orcid: http://orcid.org/0000-0001-7562-7367 